\title{
Effects of Atypical Antipsychotic Drugs on Intralipid Intake and Cocaine-Induced Hyperactivity in Rats
}

\author{
Abegale W Hartfield', Nicholas A Moore ${ }^{2}$ and Peter G Clifton*,I \\ 'Department of Psychology, University of Sussex, Brighton, UK; ${ }^{2}$ Eli Lilly \& Co, Erl Wood Manor, Windlesham, UK
}

\begin{abstract}
Clozapine and olanzapine have been shown to acutely stimulate consumption of a fat emulsion (Intralipid) by male Lister hooded rats. We initially investigated the extent of any sex difference in Intralipid hyperphagia associated with olanzapine treatment. We then examined the degree of Intralipid hyperphagia produced by a range of atypical antipsychotic drugs having different associations with human weight gain, and also determined their effects on cocaine-stimulated locomotor activity as a measure of functional dopamine antagonism in vivo. Olanzapine $(0.1-1 \mathrm{mg} / \mathrm{kg})$ stimulated Intralipid intake to an equal extent in male and female rats. Quetiapine $(10 \mathrm{mg} / \mathrm{kg})$ also stimulated Intralipid intake whereas ziprasidone $(0.3-10 \mathrm{mg} / \mathrm{kg})$ or risperidone $(0.03-0.3 \mathrm{mg} / \mathrm{kg})$ did not have this effect. All of the compounds, except quetiapine, reduced cocaine-stimulated locomotor activity but the relationship to the degree of Intralipid hyperphagia was variable. Since there was a positive relationship between Intralipid hyperphagia and the reported extent of human body weight gain, we conclude that Intralipid hyperphagia may have predictive value for this drug-associated side effect and is not related to the dopamine antagonist properties of these agents.

Neuropsychopharmacology (2006) 3 I, 1938-1945. doi:I 0. I038/sj.npp. I 300949; published online 2 November 2005
\end{abstract}

Keywords: antipsychotic; weight gain; hyperphagia; food intake; locomotor activity; rat; olanzapine

\section{INTRODUCTION}

In humans, treatment with some atypical antipsychotic drugs is associated with weight-gain (Hemphill et al, 1975; Claus et al, 1992; Beasley et al, 1996; Kraus et al, 1999). Allison et al (1999) performed a meta-analysis of published data suggesting that clozapine and olanzapine are associated with the greatest weight-gain, followed by quetiapine and risperidone; while haloperidol treatment produces only modest weight gain and ziprasidone appears to be weight neutral in most patients. Similar conclusions have been reached in reviews by Taylor and McAskill (2000) and Wetterling (2001); specifically that the rank order for weight-gain liability in humans is, highest first: clozapine and olanzapine, quetiapine, risperidone, haloperidol, and ziprasidone.

The mechanism(s) responsible for weight gain associated with atypical antipsychotic compounds remain unknown. Selective dopamine $D_{2}$ receptor antagonists, such as risperidone and haloperidol, may induce persistent elevation of plasma prolactin levels. Secondary endocrine

\footnotetext{
*Correspondence: Dr PG Clifton, Department of Psychology, University of Sussex, John Maynard Smith Building, Brighton, BNI 9QG, UK, Tel: + 441273 678396, Fax: + 44127367861 I.

E-mail: pete@sussex.ac.uk

Received 5 May 2005; revised 7 September 2005; accepted 8 September 2005

Online publication: 23 September 2005 at http://www.acnp.org/ citations/Npp092305050300/default.pdf
}

consequences of hyperprolactinaemia may dispose towards elevated body weight (Baptista, 2002). Some clinical drug trials have recorded the incidence of increased appetite as an adverse drug effect. For example, clozapine was reported to increase desire to eat in up to $75 \%$ of patients, and to result in binge eating in some patients (Bromel et al, 1998). In a systematic study of the phenomenon in humans, the daily calorie intake, diet composition (carbohydrate/ protein/fat), resting energy expenditure, and physical activity were measured in adolescent male patients with schizophrenia taking either olanzapine or haloperidol (Gothelf $e t a l, 2002$ ). The olanzapine-treated patients gained weight and showed an increase in daily calorie intake by an average of $589 \mathrm{kcal}$, an increase of nearly $28 \%$ over baseline (Gothelf et al, 2002). Diet composition (carbohydrate/ protein/fat), resting energy expenditure, and daily physical activity in these patients did not change during olanzapine treatment (Gothelf et al, 2002).

Antipsychotic drugs may also increase food intake in rodents under some circumstances. In a series of studies, Baptista and co-workers have reported that chronic sulpiride treatment increases food intake and body weight in female, but not male, rats (Parada et al, 1989) and risperidone produces a similar sex-linked weight gain (Baptista et al, 2002). Kaur and Kulkarni (2002) tested the antipsychotic compounds chlorpromazine, haloperidol, clozapine, olanzapine, risperidone, and sulpiride in female mice and found that food intake was increased over a time period ranging from $30 \mathrm{~min}$ to $2-5 \mathrm{~h}$. Previously, we have 
reported that male rats significantly increased their consumption of a fat emulsion (10\% Intralipid) during a 30-min test session following acute treatment with the atypical antipsychotic compounds clozapine or olanzapine (Hartfield et al, 2003a). There is conflicting evidence concerning gender differences in antipsychotic-associated weight gain in humans. For example, Basson et al (2001) found a greater weight gain in olanzapine treated males whereas Tollefson et al (1997) observed no gender differences during olanzapine treatment.

Here, we measured Intralipid intake in both male and female rats following olanzapine treatment in order to determine the extent of any sex difference in Intralipid hyperphagia. We then measured Intralipid intake following administration of three atypical antipsychotic drugs (quetiapine, risperidone, or ziprasidone) with lower reported associations with human body weight gain. Finally, each of these agents was examined for its ability to attenuate cocaine-induced locomotor activity. Attenuation of cocaineinduced locomotor activity is widely used as a model to study in vivo dopamine function (Ogren et al, 1984) and as a screening test for new antipsychotic drugs (Arnt, 1995; Moore, 1999). Atypical antipsychotic drugs have broad pharmacological profiles and differ in the extent of dopaminergic blockade relative to their effects at other neurotransmitter receptors (Bymaster et al, 1996; Schotte et al, 1996). Here, the degree of in vivo dopamine receptor blockade was examined by assessing the degree of attenuation of cocaine-induced locomotor activity produced using the same dose range, route, and timing of administration as used in the Intralipid drinking experiments. High levels of dopamine blockade are likely to induce motor side effects that disrupt ingestive behavior.

\section{MATERIALS AND METHODS}

\section{Subjects}

In the Intralipid intake experiments, four separate groups of Lister hooded rats (Harlan, UK) were used. The olanzapine experiment used a younger group of nine male and nine female rats in order to minimize sex differences in body size. The males weighed between 220 and $260 \mathrm{~g}$ and the females between 180 and $200 \mathrm{~g}$ at the beginning of the drug treatment phase of the experiment. Three groups of 12 male rats were used to test quetiapine (weighing between 280 and $310 \mathrm{~g}$ ), risperidone (weighing between 270 and $310 \mathrm{~g}$ ), or ziprasidone (weighing between 270 and $300 \mathrm{~g}$ ). The rats were housed in groups of three in large solid-bottomed polyethylene cages (RB2, North Kent Plastics, UK). The rats were moved to drinking cages (slightly modified RB3 cages, North Kent Plastics, UK) each day for a 30-min testing session and then placed back in their group cages. Food and water were only removed for the duration of the drinking test.

In the cocaine-induced locomotor activity experiments, four groups of forty male Lister hooded rats (Harlan, UK) were used with weights of $240-260 \mathrm{~g}$ for the olanzapine group; 235-255 $\mathrm{g}$ for the quetiapine group; $150-190 \mathrm{~g}$ for the risperidone group and 150-170 $\mathrm{g}$ for the ziprasidone group. All rats were housed in groups of four or five prior to testing. Rats were weighed and moved to the activity cages immediately before the start of the test session. Food and water were not available during testing.

\section{Drugs}

Olanzapine, quetiapine (Seroquel), and ziprasidone were all dissolved in a vehicle of $165 \mu \mathrm{l}$ of $10 \%$ lactic acid that was then brought up to volume with distilled water, sonicated if necessary and then neutralized with $1 \mathrm{M} \mathrm{NaOH}$ to obtain a final $\mathrm{pH}$ of at least 6.0. Risperidone was dissolved in a vehicle made by placing five drops of $10 \%$ lactic acid in distilled water and then the solution was sonicated briefly. Cocaine was dissolved in distilled water.

In the Intralipid intake experiments, each antipsychotic drug, or its vehicle was administered $30 \mathrm{~min}$ prior to testing. Doses used were: olanzapine $(0,0.1,0.3,1.0 \mathrm{mg} / \mathrm{kg} / \mathrm{i} . \mathrm{p}$.$) ;$ quetiapine $(0,0.3,1.0,3.0,10 \mathrm{mg} / \mathrm{kg} / \mathrm{i} . \mathrm{p}$.$) ; risperidone$ (0, $0.03,0.1,0.3 \mathrm{mg} / \mathrm{kg} / \mathrm{i} . \mathrm{p}$.$) ; and ziprasidone (0,0.1,0.3$, $1.0 \mathrm{mg} / \mathrm{kg} /$ i.p.). Dose ranges were chosen to be either below or at the low end of the dose range at which each compound produces in vivo dopamine antagonism.

In the cocaine-induced locomotor activity experiments, each antipsychotic drug or its vehicle was administered immediately prior to the rat being placed in the activity cage. Doses used for each antipsychotic drug were: olanzapine $(0.1,0.3,1.0$ and $3.0 \mathrm{mg} / \mathrm{kg} / \mathrm{i} . \mathrm{p}$.); quetiapine $(1.0,3.0,10.0$ and $30.0 \mathrm{mg} / \mathrm{kg} /$ i.p. $)$; risperidone $(0.1,0.3,1.0$ and $3.0 \mathrm{mg} / \mathrm{kg} / \mathrm{i} . \mathrm{p}$.$) ; and ziprasidone (0.3,1.0,3.0$ and $10.0 \mathrm{mg} / \mathrm{kg} /$ i.p.). Cocaine ( $40 \mathrm{mg} / \mathrm{kg} /$ i.p.) was administered to all animals $30 \mathrm{~min}$ later.

\section{Intralipid Intake Experiments}

The rats were moved to drinking cages (modified RB3 cages, North Kent Plastics, UK) each day for a 30-min testing session and then placed back in their group cages. Animals were habituated to daily presentation of a $10 \%$ Intralipid (Fresenius Kabi Ltd, Warrington, UK) emulsion in the drinking cages for 14 days prior to starting the experiment. Intralipid is supplied in a $20 \%$ commercial preparation $(2 \mathrm{kcal} / \mathrm{ml})$ and to obtain a $10 \%$ Intralipid emulsion $(1.0 \mathrm{kcal} / \mathrm{ml})$ the refrigerated supply of $20 \%$ preparation was diluted each day with fresh tap water. Intralipid consists of purified soybean oil, purified egg phospholipids, and glycerol forming a stable emulsion that makes it useful in drinking studies.

Each animal acted as its own control and received each drug dose (total of three drug administrations) or vehicle in an ascending Latin square counterbalanced design with treatments separated by a minimum of $48 \mathrm{~h}$. Animals in the quetiapine group were treated with an extra dose after a break of several weeks. The quetiapine-treated animals were habituated again, in the same way to daily presentation of $10 \%$ Intralipid in the drinking cages. Each animal then received quetiapine $10 \mathrm{mg} / \mathrm{kg}$ or its vehicle in a counterbalanced design with treatments separated by a minimum of $48 \mathrm{~h}$.

The rats were moved to the drinking cages immediately prior to the 30-min test session each day. The drinking cages and procedure are similar to that already described (Lee and Clifton, 1992; Hartfield et al, 2003a) in that the test cages are standard solid-bottomed cages having a stainless- 
steel drinking spout attached to one side wall. Intralipid emulsion was delivered from a reservoir to the spout by a peristaltic pump via polythene tubing. A microprocessor system controlled pump activation by detecting licks of the spout and switching the pump on for $0.5 \mathrm{~s}$. Number of licks and number of pump activations were both noted independently by the recording software to a resolution of $10 \mathrm{~ms}$. The pumps delivered $1.40 \mathrm{~g}$ of emulsion per minute (or $11.7 \mathrm{mg}$ per $0.5 \mathrm{~s}$ pump activation) thus allowing pump activation to be used as a measure of consumption. The delivery rate is just under the maximal rate at which rats can drink from a spout. Rats were placed into the drinking cages in quick succession, facing away from the spouts and drinking sessions start in all cages simultaneously by remote control as the experimenter left the cubicle.

Behavioural activity was measured using a cage-rack photobeam activity system (PAS; San Diego Instruments, San Diego, CA) that consisted of twenty perspex cages $\left(355 \times 235 \times 190 \mathrm{~mm}^{3}\right)$ placed inside a photobeam frame. Locomotor activity was recorded from the time rats were placed into the activity cages, immediately after administration of the relevant antipsychotic drug. After $30 \mathrm{~min}$ rats were dosed with cocaine and replaced into the same activity cage. After $2 \mathrm{~h}$, activity recording finished and the rats were removed. Each cage had four horizontal photobeams $1.5 \mathrm{~cm}$ above the cage floor and each time a beam was broken, an automatic counter mechanism was triggered. PAS monitored activity throughout the test session and provided total activity counts every $10 \mathrm{~min}$ and also a distinction between fine movements (repeated breaking of the same photobeam caused by grooming or stereotype) and ambulations (breaking of consecutive beams). Testing took part in the light part of the photoperiod. No food or water was available during the activity experiments and rats were not habituated to the activity cages prior to testing, as this would have extinguished exploratory behavior of the novel environment.

A between-subjects design was employed and each animal was allocated at random to receive one dose of antipsychotic or its vehicle. There were a total of eight animals per antipsychotic dose treatment group. In all, 20 rats were tested at one time, and two groups of 20 were run on each test day.

\section{Analysis}

In the Intralipid intake experiments, two-way (drug $\times$ gender) analyses of variance (ANOVA) with repeated measures on drug conditions, followed by planned paired $t$-tests (Bonferroni correction), were used to compare olanzapine treatments to vehicle treatment with respect to total Intralipid intake. One-way analyses of variance (ANOVA) with repeated measures on drug conditions followed by post hoc Dunnett's $t$-tests were used to compare treatment means to vehicle with respect to total Intralipid intake following quetiapine, risperidone, or ziprasidone treatments.

In the cocaine-induced locomotor activity experiments, one-way ANOVAs were used to analyze total activity counts following cocaine administration for each treatment.

To determine the relationship between clinically-observed weight gain and Intralipid consumption, we took data from
Allison et al (1999) and Wetterling (2001) for human weight gain. For the analysis from the data of Allison et al (1999), we used their preferred estimate of weight gain over 10 weeks, although the estimate for quetiapine depended on a study with shorter duration (see Table 4, footnote a, ). The minimal effective dose for Intralipid hyperphagia was taken from the present data or from Hartfield et al (2003a). Agents that did not enhance intake were assigned a value of 0 and we then calculated a Pearson correlation coefficient.

\section{RESULTS}

\section{Olanzapine}

Olanzapine increased Intralipid intake in both male and female rats $(\mathrm{F}(3,48)=13.96, p<0.001$; Figure 1a) but there was no gender difference $(\mathrm{F}(1,16)=3.75$, ns) and no interaction (drug $\times$ gender) $(\mathrm{F}(3,48)=0.33$, ns). Male rats demonstrated increases of $16 \%$ (ns) at $0.1 \mathrm{mg} / \mathrm{kg}, 32 \%$ $(p<0.05)$ at $0.3 \mathrm{mg} / \mathrm{kg}$, and $51 \%(p<0.01)$ at $1.0 \mathrm{mg} / \mathrm{kg}$ of olanzapine. Female rats displayed very similar elevations of $27 \%(\mathrm{~ns})$ at $0.1 \mathrm{mg} / \mathrm{kg}, 40 \%(p<0.01)$ at $0.3 \mathrm{mg} / \mathrm{kg}$, and $51 \%$ at $1.0 \mathrm{mg} / \mathrm{kg}$ of olanzapine $(p<0.01)$.

Total cocaine-induced locomotor activity counts were reduced during olanzapine treatment $(\mathrm{F}(4,35)=5.57, p=0.001$;
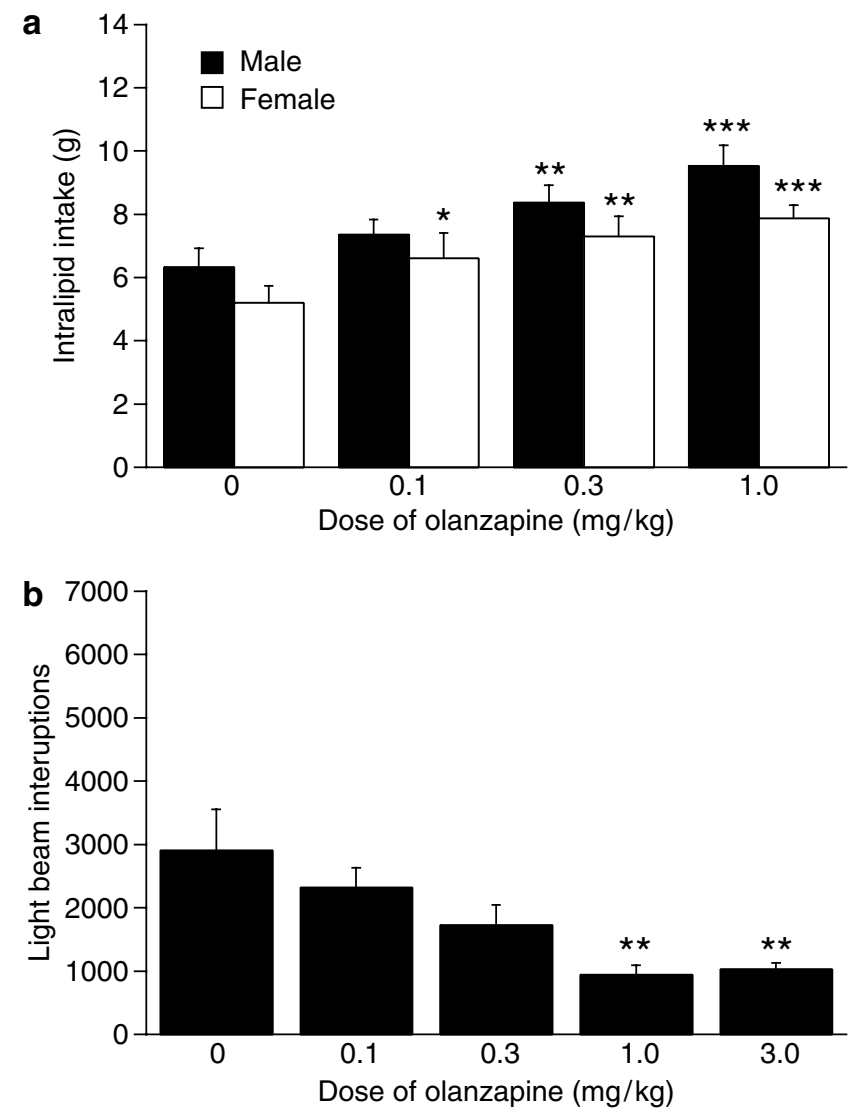

Figure I (a) Mean 10\% Intralipid intake (in grams) in males and females following administration of olanzapine. (b) The effect of olanzapine treatment on cocaine-induced locomotor activity in males only, shown as total number of light beam interruptions, after cocaine administration. Vertical lines show standard errors. * indicates significant difference $(p<0.05)$ from vehicle. $* * *$ indicates significantdifference $(p<0.0 \mathrm{I})$ from vehicle. ${ }^{* * * *}$ indicates significant difference $(p<0.00 I)$ from vehicle. 

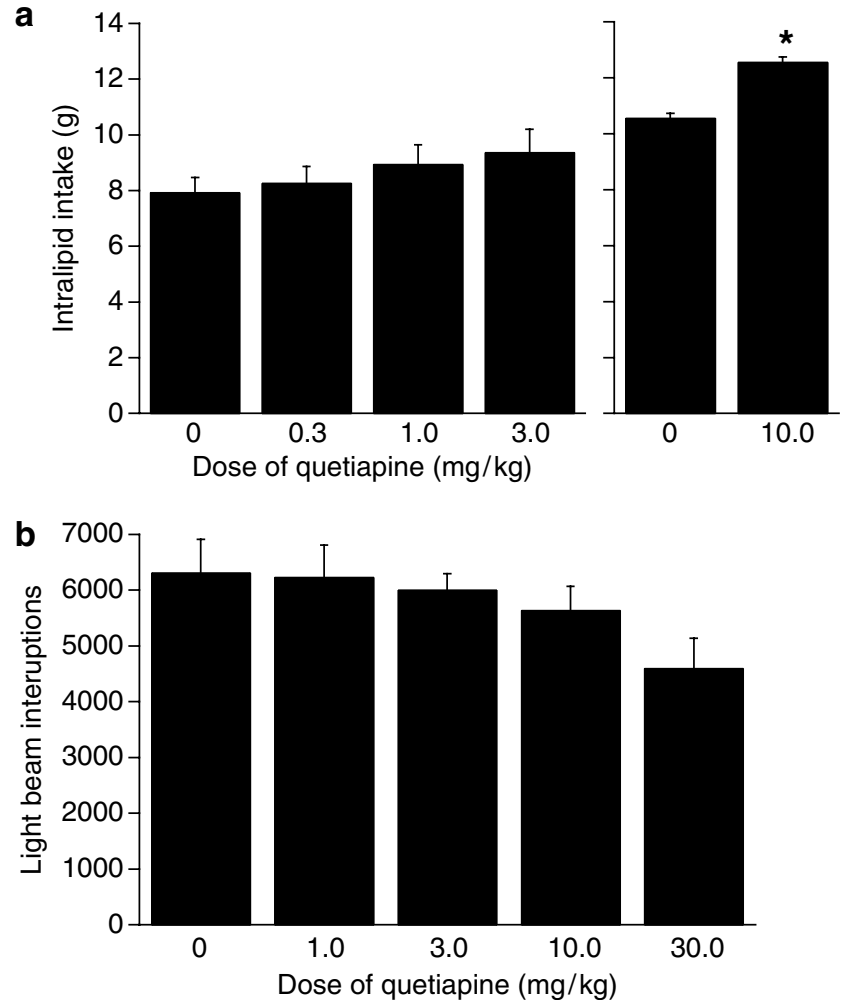

Figure 2 (a) Mean 10\% Intralipid intake (in grams) following administration of quetiapine. (b) The effect of quetiapine treatment on cocaineinduced locomotor activity, shown as total number of light beam interruptions, after cocaine administration. Vertical lines show standard errors. * indicates significant difference $(p<0.05)$ from vehicle.

Figure $1 \mathrm{~b})$ and this was significant at $1.0 \mathrm{mg} / \mathrm{kg}(p<0.01)$ and $3.0 \mathrm{mg} / \mathrm{kg}(p<0.01)$.

\section{Quetiapine}

Quetiapine increased Intralipid intake in a dose-related manner, $4 \%$ at $0.3 \mathrm{mg} / \mathrm{kg}, 11 \%$ at $1.0 \mathrm{mg} / \mathrm{kg}$, and $17 \%$ at $3.0 \mathrm{mg} / \mathrm{kg}$. However, in the first dose range tested, this did not quite reach statistical significance $(F(3,32)=2.72$, $p=0.061$; Figure 2a). When these animals were retested 3 weeks later, a statistically significant increase in intake of $15 \%$ occurred after quetiapine treatment at $10 \mathrm{mg} / \mathrm{kg}$ $(\mathrm{F}(1,11)=9.72, p=0.01$; Figure $2 \mathrm{a})$. Total cocaine-induced locomotor activity counts were not significantly reduced by quetiapine at any dose $(F(4,35)=1.93$, ns; Figure $2 b)$.

\section{Risperidone}

Risperidone did not alter Intralipid intake $(\mathrm{F}(3,33)=1.95$, ns; Figure 3a). Total cocaine-induced locomotor activity counts were reduced by risperidone $(F(4,35)=20.25$, $p<0.001$; Figure $3 \mathrm{~b}$ and this was significant at $0.3 \mathrm{mg} / \mathrm{kg}$ $(p<0.05)$ and $1.0 \mathrm{mg} / \mathrm{kg}(p<0.01)$ and $3.0 \mathrm{mg} / \mathrm{kg}(p<0.01)$.

\section{Ziprasidone}

Ziprasidone did not alter Intralipid intake at any dose $(\mathrm{F}(3,33)=0.12$, ns; Figure $4 \mathrm{a})$. Total cocaine-induced
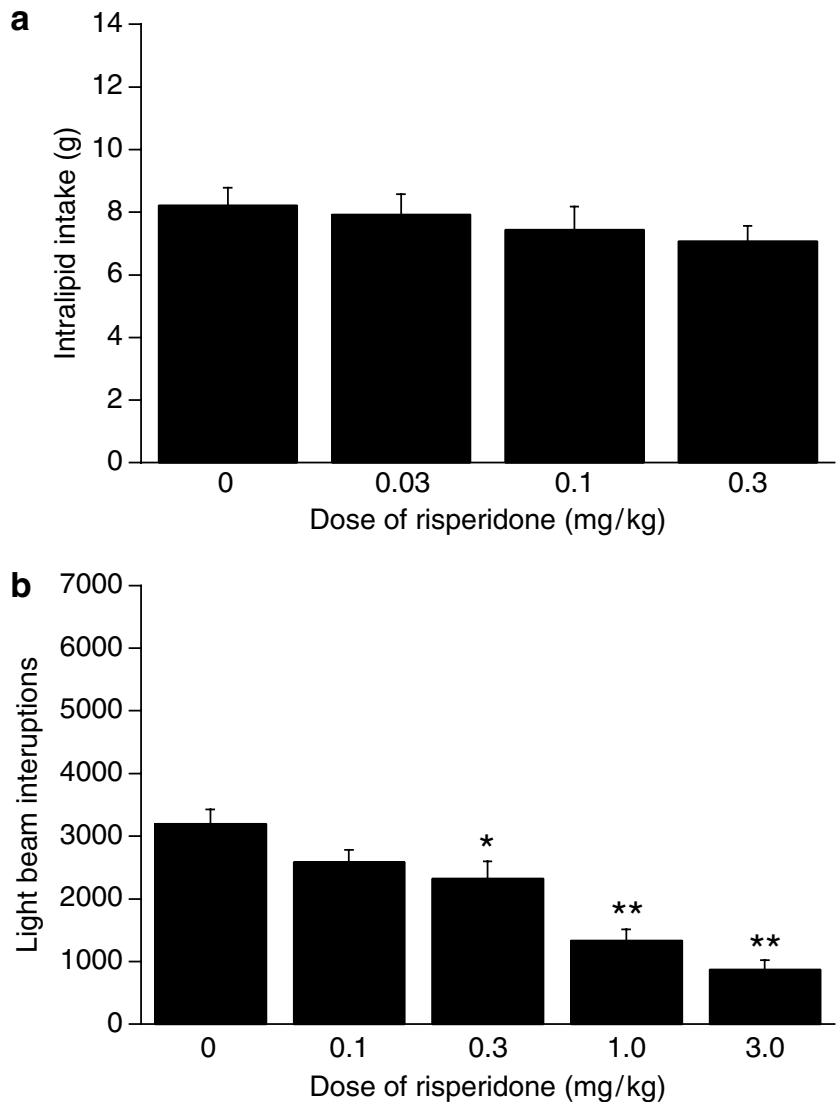

Figure 3 (a) Mean 10\% Intralipid intake (in grams) following administration of risperidone. (b) The effect of risperidone treatment on cocaineinduced locomotor activity, shown as total number of light beam interruptions, after cocaine administration. Vertical lines show standard errors. * indicates significant difference $(p<0.05)$ from vehicle. ** indicates significant difference $(p<0.01)$ from vehicle.

locomotor activity counts were reduced by ziprasidone treatment $(\mathrm{F}(4,35)=8.77, p<0.001$; Figure $4 \mathrm{~b})$ and this was significant at $3 \mathrm{mg} / \mathrm{kg}(p<0.01)$ and $10 \mathrm{mg} / \mathrm{kg}(p<0.01)$. (Table 1)

Relationship between Intralipid Intake in Rats and Antipsychotic-associated Weight-gain in Humans.

Intralipid intake (at the highest value obtained) in rats, as reported above for olanzapine, quetiapine, risperidone, and ziprasidone and in Hartfield et al (2003a) for clozapine and haloperidol, has a nonsignificant positive correlation $(r=0.793$, ns; Table 2$)$ with the 10 -week human weight-gain liabilities associated with administration of these compounds (Allison et al, 1999). There is a significant positive correlation ( $r=0.981, p<0.005$; Table 2$)$ between Intralipid hyperphagia and the amount of weight-gain per month in humans treated with clozapine, olanzapine, quetiapine, risperidone, or ziprasidone (Wetterling, 2001).

\section{DISCUSSION}

The data presented here show that olanzapine is equally effective in enhancing the intake of Intralipid in male and female rats over the dose range of $0.1-1.0 \mathrm{mg} / \mathrm{kg}$. In male rats, risperidone or ziprasidone had no significant effect, and a nonsignificant tendency towards reduced Intralipid 

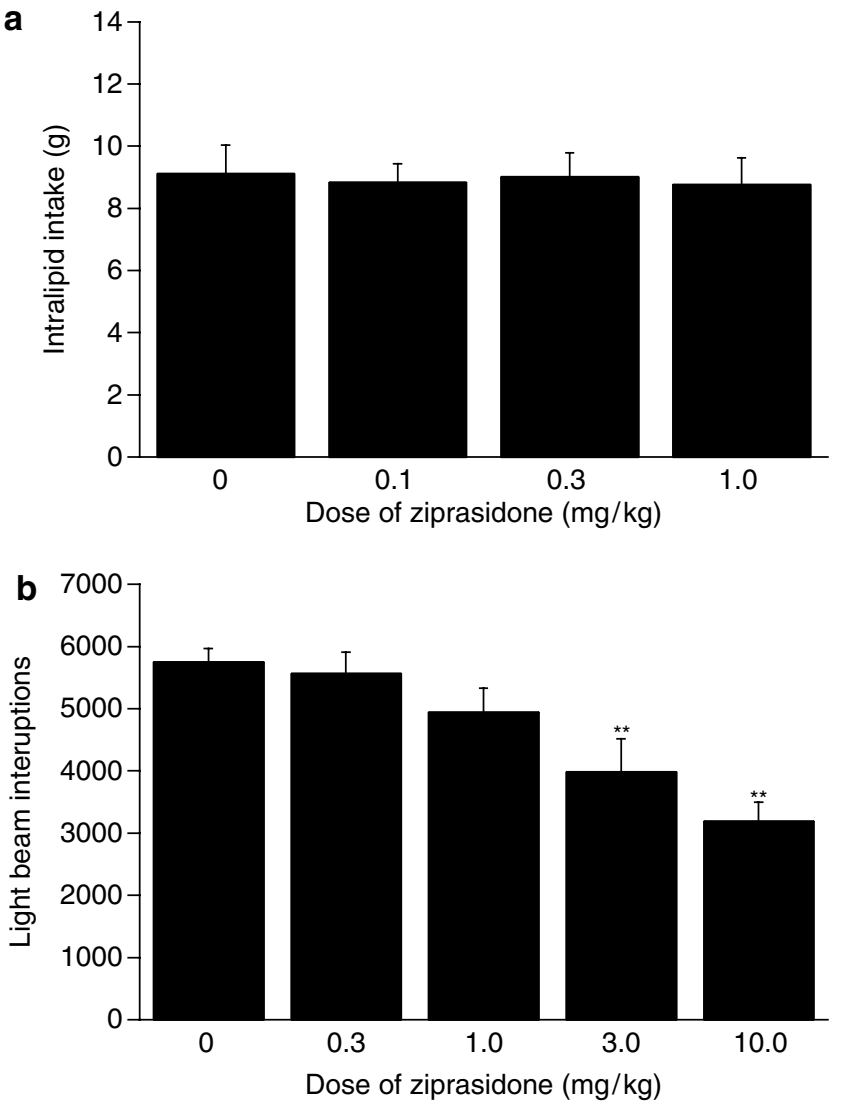

Figure 4 (a) Mean I0\% Intralipid intake (in grams) following administration of ziprasidone. (b) The effect of ziprasidone treatment on cocaineinduced locomotor activity, shown as total number of light beam interruptions, after cocaine administration. Vertical lines show standard errors. *** indicates significant difference $(p<0.0 \mathrm{I})$ from vehicle.

Table I The Effect of Various Antipsychotic Agents on Intralipid Drinking and Cocaine Hyperactivity in Lister Hooded Rats

\begin{tabular}{lcc}
\hline Compound & $\begin{array}{c}\text { Intralipid drinking } \\
\text { (EDmin) }\end{array}$ & $\begin{array}{c}\text { Suppression of cocaine } \\
\text { hyperactivity (EDmin) }\end{array}$ \\
\hline Clozapine & 0.3 & 1.0 \\
Haloperidol & $\mathrm{NE}^{\mathrm{a}}$ & 0.125 \\
Olanzapine & 0.3 & 1.0 \\
Risperidone & $\mathrm{NE}$ & 0.3 \\
Quetiapine & 10 & $>30$ \\
Ziprasidone & $\mathrm{NE}$ & 3.0 \\
\hline
\end{tabular}

${ }^{\mathrm{a}} \mathrm{NE}=$ No stimulatory effect on Intralipid drinking at doses tested.

intake at higher doses, whereas quetiapine produced a significant enhancement of intake at a dose of $10.0 \mathrm{mg} / \mathrm{kg}$. Each drug, with the exception of quetiapine, reduced cocaine-stimulated locomotor activity, although the relationship between the effective doses in the two paradigms was variable.

Olanzapine, clozapine (Allison et al, 1999; Wetterling, 2001), quetiapine (Borison et al, 1996; Arvanitis and Miller, 1997; Small et al, 1997; McIntyre et al, 2003) and
Table 2 The Relationship of Effects on Intralipid Drinking and Human Weight Gain

\begin{tabular}{lccc}
\hline Compound & $\begin{array}{c}\text { Stimulation of } \\
\text { Intralipid } \\
\text { drinking (g) }\end{array}$ & $\begin{array}{c}\text { Weight gain } \\
\text { (Allison et al, } \\
\text { (999) (kg) }\end{array}$ & $\begin{array}{c}\text { Weight gain } \\
\text { (Wetterling, } \\
\text { 200I) (kg) }\end{array}$ \\
\hline Clozapine & 1.76 & 4.45 & 1.70 \\
Haloperidol & 0.00 & 1.08 & - \\
Olanzapine & 3.65 & 4.15 & 2.30 \\
Risperidone & 0.00 & 2.10 & 1.00 \\
Quetiapine & 1.80 & 2.18 & 1.80 \\
Ziprasidone & 0.00 & 0.04 & 0.80 \\
\hline
\end{tabular}

The relationship of the increase in Intralipid intake $(\mathrm{g})$ in rats following acute drug administration to weight-gain in humans $(\mathrm{kg})$ after 10 -weeks of treatment with clozapine, olanzapine, quetiapine, risperidone, ziprasidone or haloperidol (Allison et al, 1999) and to weight-gain per month in humans (kg) after treatment with clozapine, olanzapine, quetiapine, risperidone or ziprasidone (Wetterling, 200I).

risperidone (Claus et al, 1992; Peuskens, 1995; Emsley, 1999) treatments are associated with weight gain in human males and females. However the weight-gain associated with risperidone treatment is less than that associated with clozapine, olanzapine, or quetiapine (Allison et al, 1999; Taylor and McAskill, 2000; Wetterling, 2001). Ziprasidone has a weight-neutral effect in most humans (Keck et al, 1998; Daniel et al, 1999).

There are several hypotheses concerning the mechanisms responsible for body weight gain associated with antipsychotic drug treatment. Compounds possessing potent $\mathrm{D}_{2}$ receptor affinity, such as risperidone, may produce persistent and substantial elevations in plasma prolactin (Markianos et al, 1999; Esel et al, 2001; Turrone et al, 2002) that may predispose patients towards increased body weight (Baptista, 2002). In female rats, chronic treatment with several antipsychotic drugs, including sulpiride or haloperidol, is associated with increased body weight (Baptista et al, 1987). This effect is not seen in male rats and it is likely that the decreased oestradiol levels in females that result from increased prolactin levels are critical since gonadectomy abolishes the differential effect of sulpiride in male and female rats (Parada et al, 1989). However, the Intralipid drinking results reported here demonstrate that the hyperphagic response of male rats to olanzapine is identical to that of female rats, suggesting that a different mechanism is involved. In addition, the increased intake occurs within minutes of drug administration and is therefore unlikely to involve the secondary endocrine effects of raised prolactin levels. In humans, treatment with olanzapine, clozapine, or quetiapine is not associated with persistent or potent hyperprolactinaemia (Markianos et al, 1999; Esel et al, 2001; Turrone et al, 2002) and hence is unlikely to be the mechanism responsible for the association of weight gain with drug treatment.

Preliminary evidence in humans (Gothelf et al, 2002) suggests that, at least for olanzapine, stimulation of appetite and a consequent increase in food intake may play an important role in the body weight gain associated with drug treatment. Convergent data from rodent studies support 
this hypothesis. Low doses of neuroleptics may enhance acquisition of a food rewarded place preference (Guyon et al, 1993). Olanzapine delays the slowing of running speed that occurs in rats performing a simple food-rewarded runway task as they become sated (Thornton-Jones et al, 2002). In a similar way olanazapine enhances consumption of Intralipid in a way that suggests delayed onset of satiation (Hartfield et al, 2003a). Cyproheptidine can stimulate Intralipid consumption in the same test situation as used here (Hartfield et al, 2003b) and is also known to stimulate appetite in humans.

An additional physiological action of some antipsychotic compounds is to induce hyperglycemia. In mice, this effect is pronounced following administration of clozapine or quetiapine, but less marked following risperidone and absent following haloperidol or sulpiride (Dwyer and Donohoe, 2003) administration. It has been suggested that a major part of the effect arises from inhibition of glucose transport into the cell. If this hypothesis is correct, then it is likely to lead to cellular glucoprivation. Other treatments that lead to glucoprivation are known to increase appetite and food intake. For example, 2-deoxyglucose (200 mg) increases blood glucose from 90 to $170 \mathrm{mg} \%$ and increases food intake in a short-term test from 1.5 to $5.5 \mathrm{~g}$ (Sanders and Ritter, 2000). Clozapine and risperidone produce comparable elevations of blood glucose in the mouse (Dwyer and Donohoe, 2003), but the behavioral consequences have not been evaluated. However, the body weight gain seen in female rats following prolonged sulpiride administration is associated with reduced blood glucose levels (Baptista et al, 2002). Thus inhibition of glucose transport could, at most, only account for some examples of weight gain associated with administration of antipsychotic compounds.

In an earlier study, we showed that olanzapine and clozapine, but not haloperidol, stimulate Intralipid consumption in rats (Hartfield et al, 2003a). The present data extends this comparison by showing that risperidone and ziprasidone fail to enhance Intralipid consumption whereas quetiapine does stimulate Intralipid intake. It seems unlikely that the failure to observe enhanced intake during treatment with these drugs arose from an inapropriate selection of drug doses. Olanzapine enhanced Intralipid intake at 0.3 and $1 \mathrm{mg} / \mathrm{kg}$ (Table 1 ), and reduced Intralipid intake at $3 \mathrm{mg} / \mathrm{kg}$ (Hartfield et al, 2003a) while cocaine stimulated locomotor activity was reduced at 1 and $3 \mathrm{mg} / \mathrm{kg}$. Ziprasidone and risperidone were both tested for their effects on Intralipid consumption at dose ranges below those that led to reductions in cocaine-stimulated locomotor activity. Quetiapine failed to attenuate cocaine-stimulated locomotor activity at any dose although Intralipid intake was increased at $10 \mathrm{mg} / \mathrm{kg}$. The effects of these drugs on cocaine-stimulated locomotor activity resemble those reported by Arnt (1995) for amphetamine-stimulated (0.5, $2.0 \mathrm{mg} / \mathrm{kg}$ ) locomotor activity. In Arnt's study, quetiapine failed to inhibit locomotor activity stimulated by the higher dose of amphetamine, and the overall potency of the remaining compounds was very similar to that reported here. It therefore seems reasonable to conclude that individual features of the pharmacological profile of these drugs has led to the variation in stimulation of Intralipid intake.
The particular pharmacological profile that is required to stimulate Intrapid consumption, or for an association between drug treatment and human body weight gain, remain unclear. In the case of human weight gain, several authors have suggested that $5-\mathrm{HT}_{2 \mathrm{C}}$ receptor antagonism or histamine $\mathrm{H}_{1}$ antagonism may play at least a partial role (Baptista, 2002; Kroeze et al, 2003). In the case of Intralipid hyperphagia in the rat, it seems that dopamine $D_{2}$ receptor antagonism is unlikely to be necessary. Doses of olanzapine, clozapine, and quetiapine that stimulate Intralipid consumption all lie below those that are able to inhibit cocainestimulated locomotor activity (Table 1). Such locomotor activity mainly depends on inhibition of striatal dopamine transporters by cocaine and a consequent increase in stimulation of striatal dopamine $\mathrm{D}_{2}$ receptors. Clozapine, olanzapine, and quetiapine are likely to occupy at least $50 \%$ of several other neurotransmitter receptors, as measured by ex vivo quantitative autoradiography (Schotte et al, 1996) at the doses that stimulate Intralipid consumption. These include $5-\mathrm{HT}_{2 \mathrm{~A}}, 5-\mathrm{HT}_{2 \mathrm{C}}$, noradrenergic $\alpha_{1}$, and histamine $\mathrm{H}_{1}$ receptors. Each of these receptors has been implicated in the modulation of ingestive behavior.

$5-\mathrm{HT}_{2 \mathrm{~A}}$ receptor activation is not usually associated with a selective reduction in feeding behavior but most studies have used systemic administration of relatively nonselective agents that lead to non-selective disruption of ingestive responses (Simansky and Vaidya, 1990). 5- $\mathrm{HT}_{2 \mathrm{C}}$ receptor stimulation is associated with a reduction in feeding (Clifton, 1994) and 5- $\mathrm{HT}_{2 \mathrm{C}}$ receptor mutant mice develop an obesity syndrome (Tecott et al, 1995). Nevertheless, despite extensive studies using a variety of paradigms in both rats (Kennett et al, 1997) and mice (Hewitt et al, 2002), there is no evidence to suggest that administration of selective $5-\mathrm{HT}_{2 \mathrm{C}}$ antagonists leads to a stimulation of ingestive behavior. In the rat, stimulation of noradrenergic $\alpha 1$ receptors within the $\mathrm{PVN}$ is associated with reduction of feeding and diurnal changes in noradrenergic $\alpha 1$ receptor binding have a clearly defined inverse association with diurnal changes in feeding (Morien et al, 1999). However, administration of noradrenergic $\alpha 1$ receptor antagonists, such as prazosin, does not enhance feeding, although more general manipulations of the noradrenaline transporter may have this effect (Wellman, 2000). Finally, the histamine $\mathrm{H}_{1}$ receptor is also implicated in the control of feeding behavior. Nonselective $\mathrm{H}_{1}$ antagonists, such as cyproheptidine, enhance feeding behavior in the rat (Hartfield et al, $2003 \mathrm{~b}$ ), and $\mathrm{H}_{1}$ agonists reduce feeding behavior (Morimoto et al, 2001). These studies suggest that the hyperphagic action of atypical antipsychotics may depend on their complex pharmacological profile. Such a conclusion would be consistent with the analyses of human data which have concluded that antipsychotic action at a single receptor can only provide a partial explanation for the association with human weight gain (Baptista, 2002; Kroeze et al, 2003).

Our data suggests that Intralipid consumption by rats following administration of an atypical antipsychotic may have some utility in predicting human weight gain as a consequence of antipsychotic-associated increases in appetite. Thus, the rank order for facilitation of Intralipid consumption, and for association with human weight gain is identical in our small drug sample. Risperidone and haloperidol represent two departures from accurate predic- 
tion since both are associated with some human weight gain, but fail to enhance Intralipid consumption. As discussed above, this probably arises from the fact that weight gain may be enhanced by one of several independent mechanisms, and that these two potent dopamine $D_{2}$ receptor antagonists may induce weight gain as a consequence of longer-term endocrine changes, rather than through a stimulation of appetite.

In summary, we have demonstrated that several atypical antipsychotic drugs that are associated with human weight gain following chronic administration also stimulate Intralipid consumption in rats. Several other drugs with limited weight gain liability fail to enhance Intralipid consumption. The neurochemical mechanism for the effect on Intralipid consumption may involve antagonist action at $5-\mathrm{HT}_{2 \mathrm{C}}$, noradrenergic $\alpha 1$, and/or histamine $\mathrm{H}_{1}$ receptors. Since treatment of humans with clozapine or olanzapine is also now known to be associated with stimulation of appetite, it seems possible that Intralipid hyperphagia in the rat may have some predictive value in assessing the liability of novel atypical compounds to affect body weight.

\section{ACKNOWLEDGEMENTS}

AWH was supported by an MRC Collaborative Studentship with Eli Lilly \& Co.

\section{REFERENCES}

Allison DB, Mentore JL, Heo M, Chandler LP, Cappelleri JC, Infante MC et al (1999). Antipsychotic-induced weight gain: a comprehensive research synthesis. Am J Psychiatry 156: 16861696.

Arnt J (1995). Differential effects of classical and newer antipsychotics on the hypermotility induced by two dose levels of D-amphetamine. Eur J Pharmacol 283: 55-62.

Arvanitis LA, Miller BG (1997). Multiple fixed doses of 'Seroquel' (quetiapine) in patients with acute exacerbation of schizophrenia: a comparison with haloperidol and placebo. The Seroquel Trial 13 Study Group. Biol Psychiatry 42: 233-246.

Baptista T (2002). Mechanisms of weight gain induced by antipsychotic drugs. J Clin Psychiatry 63: 245-246.

Baptista T, Araujo de Baptista E, Ying Kin NM, Beaulieu S, Walker $\mathrm{D}$, Joober R et al (2002). Comparative effects of the antipsychotics sulpiride or risperidone in rats. I: bodyweight, food intake, body composition, hormones and glucose tolerance. Brain Res 957: 144-151.

Baptista T, Parada M, Hernandez L (1987). Long term administration of some antipsychotic drugs increases body weight and feeding in rats. Are D2 dopamine receptors involved? Pharmacol Biochem Behav 27: 399-405.

Basson BR, Kinon BJ, Taylor CC, Szymanski KA, Gilmore JA, Tollefson GD (2001). Factors influencing acute weight change in patients with schizophrenia treated with olanzapine, haloperidol, or risperidone. J Clin Psychiatry 62: 231-238.

Beasley Jr CM, Sanger T, Satterlee W, Tollefson G, Tran P, Hamilton S (1996). Olanzapine versus placebo: results of a double-blind, fixed-dose olanzapine trial. Psychopharmacology 124: 159-167.

Borison RL, Arvanitis LA, Miller BG (1996). ICI 204,636, an atypical antipsychotic: efficacy and safety in a multicenter, placebo-controlled trial in patients with schizophrenia. U.S. SEROQUEL Study Group. J Clin Psychopharmacol 16: 158-169.
Bromel T, Blum WF, Ziegler A, Schulz E, Bender M, Fleischhaker C et al (1998). Serum leptin levels increase rapidly after initiation of clozapine therapy. Mol Psychiatry 3: 76-80.

Bymaster FP, Calligaro DO, Falcone JF, Marsh RD, Moore NA, Tye NC et al (1996). Radioreceptor binding profile of the atypical antipsychotic olanzapine. Neuropsychopharmacology 14: 87-96.

Claus A, Bollen J, De Cuyper H, Eneman M, Malfroid M, Peuskens J et al (1992). Risperidone versus haloperidol in the treatment of chronic schizophrenic inpatients: a multicentre double-blind comparative study. Acta Psychiatr Scand 85: 295-305.

Clifton PG (1994). The neuropharmacology of meal patterning. In: Cooper SJ, Hendrie CA (eds). Ethology and Psychopharmaco$\log y$. Wiley: Chichester.

Daniel DG, Zimbroff DL, Potkin SG, Reeves KR, Harrigan EP, Lakshminarayanan M (1999). Ziprasidone $80 \mathrm{mg} /$ day and $160 \mathrm{mg} /$ day in the acute exacerbation of schizophrenia and schizoaffective disorder: a 6-week placebo-controlled trial. Ziprasidone Study Group. Neuropsychopharmacology 20: 491-505.

Dwyer DS, Donohoe D (2003). Induction of hyperglycemia in mice with atypical antipsychotic drugs that inhibit glucose uptake. Pharmacol Biochem Behav 75: 255-260.

Emsley RA (1999). Risperidone in the treatment of first-episode psychotic patients: a double-blind multicenter study. Risperidone Working Group. Schizophr Bull 25: 721-729.

Esel E, Basturk M, Saffet Gonul A, Kula M, Tayfun Turan M, Yabanoglu I et al (2001). Effects of olanzapine and haloperidol on serum prolactin levels in male schizophrenic patients. Psychoneuroendocrinology 26: 641-647.

Gothelf D, Falk B, Singer P, Kairi M, Phillip M, Zigel L et al (2002). Weight gain associated with increased food intake and low habitual activity levels in male adolescent schizophrenic inpatients treated with olanzapine. Am J Psychiatry 159: 1055 1057.

Guyon A, Assouly-Besse F, Biala G, Puech AJ, Thiebot MH (1993). Potentiation by low doses of selected neuroleptics of foodinduced conditioned place preference in rats. Psychopharmacology 110: 460-466.

Hartfield AW, Moore NA, Clifton PG (2003a). Effects of clozapine, olanzapine and haloperidol on the microstructure of ingestive behaviour in the rat. Psychopharmacology 167: 115-122.

Hartfield AW, Moore NA, Clifton PG (2003b). Serotonergic and histaminergic mechanisms involved in intralipid drinking? Pharmacol Biochem Behav 76: 251-258.

Hemphill RE, Pascoe FD, Zabow T (1975). An investigation of clozapine in the treatment of acute and chronic schizophrenia and gross behaviour disorders. S Afr Med J 49: 2121-2125.

Hewitt KN, Lee MD, Dourish CT, Clifton PG (2002). Serotonin 2C receptor agonists and the behavioural satiety sequence in mice. Pharmacol Biochem Behav 71: 691-700.

Kaur G, Kulkarni SK (2002). Studies on modulation of feeding behavior by atypical antipsychotics in female mice. Prog Neuropsychopharmacol Biol Psychiatry 26: 277-285.

Keck Jr P, Buffenstein A, Ferguson J, Feighner J, Jaffe W, Harrigan $\mathrm{EP}$ et al (1998). Ziprasidone 40 and $120 \mathrm{mg} / \mathrm{day}$ in the acute exacerbation of schizophrenia and schizoaffective disorder: a 4-week placebo-controlled trial. Psychopharmacology 140: 173-184.

Kennett GA, Wood MD, Bright F, Trail B, Riley G, Holland V et al (1997). SB 242084, a selective and brain penetrant 5-HT2C receptor antagonist. Neuropharmacology 36: 609-620.

Kraus T, Haack M, Schuld A, Hinze-Selch D, Kuhn M, Uhr M et al (1999). Body weight and leptin plasma levels during treatment with antipsychotic drugs. Am J Psychiatry 156: 312-314.

Kroeze WK, Hufeisen SJ, Popadak BA, Renock SM, Steinberg S, Ernsberger P et al (2003). H1-histamine receptor affinity predicts short-term weight gain for typical and atypical antipsychotic drugs. Neuropsychopharmacology 28: 519-526. 
Lee MD, Clifton PG (1992). Free-feeding and free-drinking patterns of male rats following treatment with opiate kappa agonists. Physiol Behav 52: 1179-1185.

Markianos M, Hatzimanolis J, Lykouras L (1999). Switch from neuroleptics to clozapine does not influence pituitary-gonadal axis hormone levels in male schizophrenic patients. Eur Neuropsychopharmacol 9: 533-536.

McIntyre RS, Trakas K, Lin D, Balshaw R, Hwang P, Robinson $\mathrm{K}$ et al (2003). Risk of weight gain associated with antipsychotic treatment: results from the Canadian National Outcomes Measurement Study in Schizophrenia. Can J Psychiatry 48: 689-694.

Moore NA (1999). Behavioural pharmacology of the new generation of antipsychotic agents. Br J Psychiatry 174(Suppl 38): 5-11.

Morien A, Cassone VM, Wellman PJ (1999). Diurnal changes in paraventricular hypothalamic alpha1 and alpha2-adrenoceptors and food intake in rats. Pharmacol Biochem Behav 63: 33-38.

Morimoto T, Yamamoto Y, Yamatodani A (2001). Brain histamine and feeding behavior. Behav Brain Res 124: 145-150.

Ogren SO, Hall H, Kohler C, Magnusson O, Lindbom LO, Angeby $\mathrm{K}$ et al (1984). Remoxipride, a new potential antipsychotic compound with selective antidopaminergic actions in the rat brain. Eur J Pharmacol 102: 459-474.

Parada MA, Hernandez L, Paez X, Baptista T, Puig de Parada M et al (1989). Mechanism of the body weight increase induced by systemic sulpiride. Pharmacol Biochem Behav 33: 45-50.

Peuskens J (1995). Risperidone in the treatment of patients with chronic schizophrenia: a multi-national, multi-centre, doubleblind, parallel-group study versus haloperidol. Risperidone Study Group. Br J Psychiatry 166: 712-726; discussion 727-733.

Sanders NM, Ritter S (2000). Repeated 2-deoxy-D-glucose-induced glucoprivation attenuates Fos expression and glucoregulatory responses during subsequent glucoprivation. Diabetes 49 : $1865-1874$.
Schotte A, Janssen PF, Gommeren W, Luyten WH, Van Gompel P, Lesage AS et al (1996). Risperidone compared with new and reference antipsychotic drugs: in vitro and in vivo receptor binding. Psychopharmacology 124: 57-73.

Simansky KJ, Vaidya AH (1990). Behavioral mechanisms for the anorectic action of the serotonin (5-HT) uptake inhibitor sertraline in rats: comparison with directly acting 5-HT agonists. Brain Res Bull 25: 953-960.

Small JG, Hirsch SR, Arvanitis LA, Miller BG, Link CG (1997). Quetiapine in patients with schizophrenia. A high- and low-dose double-blind comparison with placebo. Seroquel Study Group. Arch Gen Psychiatry 54: 549-557.

Taylor DM, McAskill R (2000). Atypical antipsychotics and weight gain - a systematic review. Acta Psychiatr Scand 101: 416-432.

Tecott LH, Sun LM, Akana SF, Strack AM, Lowenstein DH, Dallman MF et al (1995). Eating disorder and epilepsy in mice lacking 5-HT2c serotonin receptors. Nature 374: 542-546.

Thornton-Jones Z, Neill JC, Reynolds GP (2002). The atypical antipsychotic olanzapine enhances ingestive behaviour in the rat: a preliminary study. J Psychopharmacol 16: 35-37.

Tollefson GD, Beasley Jr CM, Tran PV, Street JS, Krueger JA, Tamura RN et al (1997). Olanzapine versus haloperidol in the treatment of schizophrenia and schizoaffective and schizophreniform disorders: results of an international collaborative trial. $\mathrm{Am} \mathrm{J}$ Psychiatry 154: 457-465.

Turrone P, Kapur S, Seeman MV, Flint AJ (2002). Elevation of prolactin levels by atypical antipsychotics. Am J Psychiatry 159: 133-135.

Wellman PJ (2000). Norepinephrine and the control of food intake. Nutrition 16: 837-842.

Wetterling T (2001). Bodyweight gain with atypical antipsychotics. A comparative review. Drug Safety 24: 59-73. 